cules coming up to the heater in equal numbers and with equal velocities from all directions in front, and by molecules receding from the heater equally in all directions, although with augmented velocities. Under these circumstances there would be no difference in the pressure on the front and back of the disc, except during the very brief period of adjustment.

By making this assumption Prof. Reynolds leaves the part of Hamlet out of the play; for Crookes's force arises out of the very circumstance which has been omitted, viz., that the molecules that come up to the heater or cooler, arrive in the form of a rain which predominates in a definite direction, a direction which is normal to the heater and cooler in the simple case of their being parallel, G. JOHNSTONE STONEY

\section{A Double Rainbow}

ON the 28th insti, at about 6.30 P.M. while myself and some ten or twelve other gentlemen were playing cricket, we were surprised to see what we all considered a most novel phenomenon-a double rainbow. The sky was cloudy and the weather was thundery. At the time referred to a shower of rain fell; the sun was about $10^{\circ}$ above the horizon, shining out very bril. liantly and reflecting upon the waters of St. Vincent's Gulf. Great wonder was expressed at the strange appearance, and much curiosity as to the cause.

The appearance was as follows:-There were two distinct and well-defined bows; the feet were united, but the apices were a considerable distance apart.

I am of opinion that the lower bow was caused by the direct light of the sun, while the light reflected from the sea produced the upper one.

Willunga, South Australia, November 30

\section{SCIENCE IN TRAINING COLLEGES}

$\mathrm{T}$

E Science and Art Department has just issued a circular having an important bearing on the teaching of science is to take in our training colleges, and therefore also in elementary schools.

The Lords of the Committee of Council on Education believe that the time has arrived when a special examination should be instituted at a period of the year better adapted to the training colleges than May, and that the nature of the examination and the payments made on the results should be modified to suit the circumstances of those colleges. They have therefore determined that in future a special examination in science shall be held in training colleges in December, immediately before the ordinary Christmas examination.

The examination will not be open to acting teachers. It will be held in those subjects only for which a special course of instruction is provided in the time-table of the College, and will be conducted by one of her Majesty's inspectors or by an officer of the Science and Art Department. Special committees will no longer be required for the training colleges; such returns as are necessary wil be made by the principal. No student in a training college will be allowed to attend the May examinations of the Science and Art Department, except in physical geography in May, 1878 .

The examination will be confined to the following. nine subjects :- I. Mathematics. 2. Theoretical Mechanics. 3. Applied Mechanics. 4. Acoustics, Light, and Heat 5. Magnetism and Electricity. 6. Inorganic Chemistry. including Practical Chemistry. 7. Animal Physiology. 8. Elementary Botany. 9. Physiography.

No student will be permitted to take up more than two subjects in any one year, and women will not be permitted to take more than one subject in a year.

The examination, except for mathematics, will be based on the syllabus of the several subjects given in the Science Directory; but the two stages, elementary and advanced, will be treated as a whole--one paper only being set. These examination papers will be framed much as the present May papers are framed, that is to say, with a certain number of compulsory questions and a certain number of optional questions, some of the latter being more difficult and more highly marked than the rest. Questions will also be set on the method of teaching various branches of the subject.

The successful students will be placed in the first or second class, the standard for a second class being as high as that of a good second class in the present advanced stage, and for the first class of a good first class in the advanced stage. All students who pass will be registered as qualified to earn payments on results and will receive certificates, but no prizes will be given. A payment of $3 l$. will be made on account of each first class, and 1 l. ros. on account of each second class obtained by a student in a training college.

In addition to the payments for theoretical chemistry, payments will be made for practical chemistry, of the same amounts and on the same conditions as those detailed in the Science Directory, $\$$ XLV. The circular contains an appendix with a syllabus of the subjects for mathematics in training colleges. We should advise all interested in this matter to obtain a copy of the circular.

\section{SUN-SPOTS AND TERRESTRIAL MAGNETISM}

T HAVE seen only to-day the number of NATURE (vol. xvii. p. 220) containing a letter from Prof. Piazzi Smyth on the above subject. I have also just now seen for the first time a communication from M. Faye to the French Academy of Sciences on July 30 last, in which there is a reference to the same subject; this 1 regret much, as M. Faye, through an incomplete acquaintance with my investigations, has drawn conclusions from one of them which are not exact. I shall at present refer only to the subject of Prof. Smyth's letter.

M. Faye considers the difference of the periods found by Dr. Lamont and myself for the diurnal oscillations of the magnetic needle (10.45 years) and by Dr. Wolf from the sun-spots (II'II years), a sufficient proof that these cycles are not synchronous, and therefore that there is no causal connection between the two phenomena. Prof Smyth asks an explanation relatively to this difference, upon the supposition that the two periods found are the true mean durations of the cycles for the respective phenomena. This supposition, however, is erroneous, and consequently M. Faye's deductions from it fail.

I have shown in a paper cited by M. Faye ${ }^{1}$ that if we determine the epoch of the maximum diurnal oscillation of the needle from Cassini's observations made at Paris, and from Gilpin's observations made at London, we find it to have occurred in $1787^{\prime} 25$. This epoch agrees very nearly with that deduced by Dr. Wolf for the maximum of sun-spots. If we compare this epoch with that of the last maximum which occurred for both phenomena near the end of 1870 , we shall obtain a mean duration of $10^{\circ} 45$ years, upon the assumption that eight cycles happened between these two epochs. There is no difference between Dr. Wolf and the magneticians excepting upon the question whether there were eight or only seven cycles. Dr. Lamont considers that the data existing between 1787 and 1818 are worthless for a decision upon this point, and by induction from the known cycles has concluded that three cycles must have occurred in the thirty-one years 1787 to 1818 . Dr. Wolf believes there were only two. I have given the evidence which makes the existence of three extremely probable. This question has no relation whatever to the synchronism of the two phenomena.

If we could accept Dr. Wolf's view we should find, as I have shown, that the mean duration of a cycle for bot/l phenomena since 1787 would be $I_{1}^{\circ} 94$ years, whilo the sun-spot results for eight cycles detemined by Dr. 
Wolf during eighty years before 1787 give $10^{*} 23$ years (or, if we take nine cycles, 10.43 years) for the mean duration. It is by mixing these two very different means that the Zurich astronomer finds II' $I$ years, a mean that can evidently have no weight given to it. On the other hand, if Dr. Wolf is in error (as I believe he is) as to the existence of a maximum in 1797 , the mean durations for the eighty years after, and for the eighty years before 1787 agree as nearly as the accuracy of the determinations for the beginning of the eighteenth century will admit.

I beg, then, to repeat that since the time when regular series of magnetic observations were commenced, till now, there is no difference whatever between Dr. Wolf and the magneticians as to the synchronism of the two phenomena.

Under these circumstances we come to the questionAre the sun-spot maxima and minima really synchronous with those of the magnetic diurnal oscillations? I have already said that this was so in 1787 ; and, considering only the cases for which we have complete materials for comparison, beginning with Schwabe's observations of sun-spots, it was so for the maxima of $1829,1837,1848$, 1860 , and 1870 , and for the minima of $1824,1833-4(q . p$.$) ,$ $1844,1856,1866$, and it is the case for the minimum at the present time. These coincidences are far more important, as showing a common cause, than may appear at first sight from this summary.

The successive oscillations of the sun-spot variations are not performed in equal times, neither are those of the magnetic variations. Was the duration of the oscillation for the sun-spots only eight years, as from the maximum in 1829 to that of 1837 , so was that for the magnetic variations; did it amount to $12 \frac{1}{2}$ years nearly, for the sun-spots, as from the minimum of 1844 to that of 1856 , this was also the case for the oscillations of the needle. Does the sun-spot variation proceed from a minimum to a maximum within about three and a half years as from $1833-4$ to 1837 , so does the magnetic oscillation. Does the sun-spot variation occupy nearly eight years between a maximum and the following minimum, as from 1848 to 1856 , so does the diurnal oscillation of the needle.

It will be difficult to persuade physicists that, during nearly a century the sun-spot cycle has been shortened or lengthened, and the sun-spot variations have been accelerated or retarded, so nearly together with those of the diurnal oscillations of the magnet, by accidental coincidences. No doubt the admission of the existence of a causal connection between the two phenomena is opposed to the hypothesis, which many other facts render now wholly untenable, that the magnetic variations are due to the heating action of the sun.

I am obliged to Prof. Piazzi Smyth for giving me the occasion to explain a difficulty which has troubled others as well as himself.

January 23

\section{HENRI VICTOR REGNAULT}

THE death of M. Becquerel, alluded to in our last issue, was followed on the 19th inst. by that of his friend and fellow-physicist, M. Regnault, whose name is associated so intimately with the elementary principles of our knowledge of heat. Henri Victor Regnault was born at Aix-la-Chapelle, July 2 $\mathrm{I}, 18 \mathrm{IO}$. His youth was spent in a hard battle against poverty in the effort to maintain not only himself, but his sister. While still a lad he wandered to Paris, and there obtained a position as assistant in the large drapery establishment known as Le Grand Coude, a name familiar at the present day to the lady visitors of Paris. Here ability and fidelity won for him friends, and at the age of twenty he was enabled to gratify his longings for a scientific education, and enter the Ecole Polytechnique of Paris, the Alma Mater of so many famous French savants. After a course of two years here, in 1832 he entered upon active duties in the department of mines, and was absent from Paris for the next eight years. During the latter portion of this time he occupied a professor's chair at Lyons, and had a laboratory at his disposal. Here he embraced the opportunity to enter upon the field of research in organic chemistry, which had just sprung into existence as a branch of chemical science, under the hands of Liebig, Wöhler, Laurent, Dumas, and others. While many of the chemists of the day were engaged in theoretical disputes, and the battle between the electro-chemical theory and the newly-advocated type-theory was being hotly waged, Regnault devoted himself to the accumulation of the facts so sorely needed as foundation-stones by the disputants on both sides. Among his investigations at this time may be mentioned those on the composition of meconine, piperine, cantharidine, and other alkaloids, composition of pectic acid, identity of esquisetic acid with maleic acid, properties of naphthaline-sulpho-acid, \&c. By the action of sulphuric anhydride on ethylene, he obtained the carbylsulphate, $\mathrm{C}_{2} \mathrm{H}_{4} \mathrm{~S}_{2} \mathrm{O}_{6}$, which Magnus prepared later from alcohol. His most valuable researches, however, were on the halogen derivatives in the ethyl-group, especially interesting at the time of their appearance, when the theories of substitution were timidly being advocated. Among these compounds now familiar reagents to the organic chemists were mono-chloro-ethylene-chloride, $\mathrm{CH}_{2} \mathrm{Cl} . \mathrm{CHCl}_{2}$, obtained by the action of chlorine on ethylene chloride, as well as the higher chlorinated derivatives, which offered one of the most striking instances of substitution. These were followed shortly after $\left(183^{8}\right)$ by the classical investigations on the actions of chlorine on ethyl-chloride $\mathrm{C}_{2} \mathrm{H}_{5} \mathrm{Cl}$, in which one by one all of the hydrogen atoms were successively substituted by chlorine, until the limit, $\mathrm{C}_{2} \mathrm{Cl}_{6}$ was reached. Of importance also was the change of ether, $\mathrm{C}_{4} \mathrm{H}_{10} \mathrm{O}$, into perchloroether, $\mathrm{C}_{4} \mathrm{Cl}_{10} \mathrm{O}$. Another interesting series of preparations gave the substituted ethylenes by the action of alkalies on saturated halogen derivatives, ethylenebromide for example, yielding vinyl-bromide, and hydro. bromic acid :-

$$
\mathrm{C}_{2} \mathrm{H}_{4} \mathrm{Br}_{2}+\mathrm{HKO}=\mathrm{C}_{2} \mathrm{H}_{3} \mathrm{Br}+\mathrm{KBr}+\mathrm{H}_{2} \mathrm{O} \text {. }
$$

By this method he discovered vinyl-bremide, vinyl-iodide, vinyl-chloride, dichlor-ethylene, $\mathrm{C}_{2} \mathrm{H}_{2} \mathrm{Cl}_{2}$, and trichlor-ethylene, $\mathrm{C}_{2} \mathrm{HCl}_{3}$. Finally must be mentioned his discovery of carbon-tetrachloride, $\mathrm{CCl}_{4}$, by leading chlorine into boiling chloroform. It is difficult for us at the present day to estimate the importance attached to these discoveries forty years ago, when every new. fact was a glimmer of light to the organic chemist wandering in the dark, and few series of researches have stood the test of time so well as those carried out by Regnault in his Lyons laboratory. The faithful study of minute properties, and the careful attention to physical peculiarities, already gave evidence of the tendencies which were manifested more fully in another branch of science, and the appearance of his papers in the Amnales de Chimie et Physique attracted the attention of the scientific world to the hitherto unknown provincial professor. In 1840 he was elected to replace Robiquet in the chemical section of the French Academy, and was appointed professor in the Ecole Polytechnique. In the following year he was elected to the chair of physics at the College de France. A few years later he became engineer-in-chief of mines, and in 1850 received the order of officer in the Legion of Honour.

With his removal to Paris the field of Regnault's investigations was changed. Like our own Faraday, after having obtained renown as a chemist, he suddenly turned physicist. He was scarcely established in Paris, when he began his famous series of experiments on specific heat. A few years previous, Dulong and Petit had determined the specific heat of a number of elements by 